\title{
EL PROBLEMA DE LA RENOVACIÓN DE LOS ÓRGANOS CONSTITUCIONALES
}

FERNANDO SANTAOLALLA LÓPEZ 


\section{SUMARIO}

I. PLANTEAMIENTO. II. LA SITUACIÓN LEGAL. III. LA PROPUESTA DE SANTAMARÍA PASTOR. IV. DOS REFERENCIAS: LOS CASOS DE ITALIA Y ALEMANIA. V. ALGUNAS SOLUCIONES Y SUS LIMITACIONES. VI. LA RAÍZ DEL PROBLEMA Y LA SOLUCIÓN COHERENTE. VII. INCONVENIENTES POSIBLES DE LO DEFENDIDO Y SU VALOR RELATIVO. ANEXO. RENOVACIONES ACAECIDAS DE LOS ÓRGANOS CONSTITUCIONALES. BIBLIOGRAFÍA UTILIZADA. 


\title{
EL PROBLEMA DE LA RENOVACIÓN DE LOS ÓRGANOS CONSTITUCIONALES
}

\author{
POR \\ FERNANDO SANTAOLALLA LÓPEZ \\ Letrado de las Cortes Generales \\ Profesor Titular de Derecho Constitucional de la Universidad de Alcalá
}

\section{PLANTEAMIENTO}

De todos es conocida la situación creada en órganos constitucionales de la máxima importancia, entre los cuales destacan el Tribunal Constitucional y el Consejo General del Poder Judicial (en adelante CGPJ), a cuenta del desmesurado retraso producido en la renovación de sus miembros. En concreto, el CGPJ se ha renovado en octubre de 2008 con dos años de retraso respecto a las previsiones legales y, por su parte, el tercio del Tribunal Constitucional que corresponde elegir al Senado sufre una demora de dos años ${ }^{1}$. Y no parece que esta situación vaya a enderezarse en el corto plazo vista la ausencia de consenso entre los dos principales partidos políticos, de la que ha informado profusamente la prensa en los últimos meses ${ }^{2}$.

${ }^{1}$ En el momento de revisarse este comentario, Noviembre de 2009.

2 Por ejemplo véase artículo de PABLO XIMÉNEZ DE SANDOVAL y FERNANDO GAREA en el diario El País de 1 de octubre de 2008. Por su parte, JAVIER PRADERA afirmaba que el Tribunal Constitucional y el CGPJ están al borde del naufragio en Una crisis de edad, El País de 7 de diciembre de 2008. Véase también artículo de PABLO XIMÉNEZ DE SANDOVAL y FERNANDO GAREA en El País de 11 de enero de 2009. 
La verdad es que la situación en modo alguna es nueva. Al contrario, puede decirse que tiene amplios antecedentes. Y así, por solo dar una muestra inicial, el primer Defensor del Pueblo se designó (el 30 de diciembre de 1982) con más de un año de retraso tras la aprobación de la Ley orgánica 3/1981, de 6 de abril, con una votación fallida de por medio en el Congreso de los Diputados ${ }^{3}$.

Para un repaso de las renovaciones de los órganos constitucionales acaecidas desde su establecimiento nos remitimos al resumen que figura en el anexo del presente estudio.

Pero antes de pasar a otras reflexiones sobre las causas y consecuencias de esta realidad, nos parece obligado reflejar aquí los datos de Derecho positivo que la enmarcan, esto es, la regulación sobre la elección o designación de los miembros de los órganos constitucionales. Aunque sobradamente conocidos, su presencia puede servir para contrastar con más facilidad los comentarios posteriores.

\section{LA SITUACIÓN LEGAL}

La previsión de elección y duración del mandato del CGPJ está contenida en el artículo 122.3 de la Constitución que dice así:

El Consejo General del Poder Judicial estará integrado por el Presidente del Tribunal Supremo, que lo presidirá, y por veinte miembros nombrados por el Rey, por un período de cinco años. De éstos, doce entre Jueces y Magistrados de todas las categorías judiciales, en los términos que establezca la ley orgánica; cuatro a propuesta del Congreso de los Diputados y cuatro a propuesta del Senado, elegidos en ambos casos por mayoría de tres quintos de sus miembros, entre abogados y otros juristas, todos ellos de reconocida competencia y con más de quince años de ejercicio en su profesión.

Por tanto, lo que destaca a nuestros efectos es la exigencia para su elección de una mayoría de tres quintos en las dos Cámaras y la previsión de una duración de cinco años. Nada se dice sobre una posible prórroga del mandato.

Y el artículo 122.2 se limita a establecer lo que puede regular la ley orgánica ${ }^{4}$. Entre los aspectos mencionados no figura la menor alusión a una prórroga o prolongación del mandato de cinco años, por lo que resultaría plausible entenderla excluida, máxime teniendo en cuenta su importancia. De hecho el artícu-

\footnotetext{
3 Véase Diario de Sesiones del Congreso de los Diputados de 28 de junio de 1982, p. 14680 y ss.

${ }^{4}$ Concretamente dispone: El Consejo General del Poder Judicial es el órgano de gobierno del mismo. La ley orgánica establecerá su estatuto y el régimen de incompatibilidades de sus miembros y sus funciones, en particular en materia de nombramientos, ascensos, inspección y régimen disciplinario.
} 
lo 101.2 de la Constitución prevé para el Gobierno cesado que continuará en funciones hasta la toma de posesión del nuevo Gobierno, y el artículo 116.5 regula algo parecido para las Cortes en caso de vigencia de un estado de alarma, excepción o sitio. Estas previsiones denotan la importancia de la cuestión, no susceptible de ser tratada como un aspecto adjetivo o secundario.

A pesar de ello, el artículo 115.2 de la LOPJ dispone:

El Consejo saliente continuará en funciones hasta la toma de posesión del nuevo Consejo.

Pero esta previsión, vistos los datos constitucionales, no puede interpretarse como una aceptación sin más de toda prórroga. Es más, el propio artículo 114 de la LOPJ viene a excluir en su espíritu todo lo que supere una demora reducida 5 .

Como se ve, la previsión de notificar a las Cámaras la decadencia del mandato quinquenal con una antelación tan amplia como la de seis meses - en principio sobradamente suficiente para acometer todo el proceso de propuesta y elección - apunta a una voluntas legis de que los nuevos componentes estén debidamente designados en el momento de concluir el CGPJ anterior.

Bien es verdad que al señalar que el cómputo de los cinco años se hará desde la fecha de su constitución podría hacer pensar que ésta es variable y, por tanto, que un retraso es admisible. Sin rechazar esta interpretación, nos parece que la misma solo resulta aceptable en la medida que se limite a lo que sugiere el precepto: un retraso, no en la designación, sino en el acto de constitución del CGPJ. Y aunque ciertamente este segundo puede venir provocado por el primero, el espíritu de toda la norma resulta opuesto a lo que no sea un pequeño retraso de días o acaso semanas ${ }^{6}$. Un retraso más amplio, como en los restantes órganos constitucionales, solo podría justificarse por razones extraordinarias, como que las Cortes Generales estuviesen disueltas en el momento de corresponder la elección del nuevo CGPJ, pero no por otras de carácter subalterno.

En el caso del Tribunal Constitucional encontramos una situación parecida. Por un lado, el artículo 159 de la Constitución es claro en la exigencia

\footnotetext{
5 Establece dicho artículo: El Consejo General del Poder Judicial se renovará en su totalidad cada 5 años, computados desde la fecha de su constitución. A tal efecto, y con 6 meses de antelación a la expiración del mandato del Consejo, su Presidente se dirigirá a los de las Cámaras, interesando que por éstas se proceda a la elección de los nuevos Vocales y poniendo en su conocimiento los datos del escalafón $y$ del Registro de asociaciones profesionales de Jueces y Magistrados obrantes en dicha fecha en el Consejo, que serán los determinantes para la presentación de candidaturas conforme a lo dispuesto en el articulo 112.

${ }^{6}$ En el mismo sentido JUAN ALFONSO SANTAMARÍA PASTOR 2008, p. 17.
} 
para la elección de los magistrados de mayoría de tres quintos de los miembros del Congreso y del Senado (apartado 1) y en que los magistrados del Tribunal serán designados por un periodo de nueve años (apartado 3). Para nada se alude a una posible prolongación del mandato. Es más, cuando su artículo 165 se remite a la ley orgánica no parece incluirse algo semejante ${ }^{7}$.

Por su parte, la Ley orgánica 2/1979, de 3 de octubre, del Tribunal Constitucional, conduce a la misma conclusión. No hay mención expresa o tácita de prórroga o prolongación en el apartado 1 de su artículo $17^{8}$. Por eso, al igual que en el caso del CGPJ, la previsión de notificación de la necesidad de renovación con cuatro meses de anticipación supone que la ley se ha preocupado de disponer lo necesario para que el mandato de nueve años se cumpla necesariamente. Es difícil entender en caso contrario un plazo no precisamente reducido como el de cuatro meses. Esto apunta a una renovación no postergable.

Es el apartado 2 de este artículo 17 (Los Magistrados del Tribunal Constitucional continuarán en el ejercicio de sus funciones hasta que hayan tomado posesión quienes hubieren de sucederles) el que viene a legalizar un posible retraso en la renovación del Tribunal. De hecho constituye la (endeble) base legal con la que se ha querido justificar los enormes retrasos padecidos.

Pero como ninguno de estos dos apartados puede entenderse aisladamente, sino combinadamente, hay que admitir que el 1 no puede significar que toda prolongación, por pequeña que sea, resulte inconstitucional, pues a ello se opone el 2. A su vez el retraso que admite este último, visto el espíritu del apartado 1 , debe interpretarse restrictivamente, como un retraso acaso más relacionado con la toma de posesión que con la designación propiamente dicha. Al igual que en el caso del CGPJ se trataría de retraso de días o semanas, situación en absoluto parangonable con las prórrogas de facto mencionadas al principio. Un retraso mayor podría admitirse de concurrir un hecho extraordinario, como estar disueltas las Cámaras en el momento en que procede la renovación. Pero otros retrasos no parecen amparados.

Por su parte, el régimen legal del Tribunal de Cuentas se asemeja en aspectos importantes con lo que se acaba de exponer para el CGPJ y el Tribunal

7 Este artículo establece: Una ley orgánica regulará el funcionamiento del Tribunal Constitucional, el estatuto de sus miembros, el procedimiento ante el mismo y las condiciones para el ejercicio de las acciones.

${ }^{8}$ En concreto su texto es el siguiente: Antes de los cuatro meses previos a la fecha de expiración de los nombramientos, el Presidente del Tribunal solicitará de los Presidentes de los órganos que han de hacer las propuestas para la designación de los nuevos Magistrados, que inicien el procedimiento para ello. 
Constitucional. Pero también median diferencias: no es la Constitución la que configura la mayoría exigible a las cámaras para su elección (su artículo 136. 1 se limita a disponer que dependerá directamente de las Cortes Generales) ni la que establece la duración de su mandato, limitándose el artículo 136.4 a remitirse a una ley orgánica (Una ley orgánica regulará la composición, organización y funciones del Tribunal de Cuentas). Todo lo cual supone sin duda que el legislador dispone de un mayor margen de discreción que en los dos casos anteriores.

De hecho el artículo 30.1 de la Ley Orgánica 2/1982, de 12 de mayo, del Tribunal de Cuentas, regula este aspecto, disponiendo una elección también por tres quintos y un mandato novenal ${ }^{9}$. Pero dicha Ley orgánica no añade nada sobre prórroga o prolongación del mandato, lo que en modo alguno resulta favorable a una interpretación amplia de esta posibilidad.

Es una ley ordinaria, la 7/1988, de 5 de abril, de Funcionamiento del Tribunal de Cuentas, la que amplia esta regulación, admitiendo un cierto retraso en la renovación de este órgano. Concretamente su artículo 22 admite la continuación en funciones de los consejeros ${ }^{10}$, pero dentro de unos términos que conducen a la misma conclusión que hemos sostenido para el Tribunal Constitucional: su espíritu y su letra son terminantes en la necesidad de renovación al cumplirse el mandato de nueve años, sin que el mantenimiento en el ejercicio de las funciones pueda admitirse más que para periodos prudentes, en todo caso breves, de tiempo.

Por su parte, el perfil legal del Defensor del Pueblo también coincide en sus rasgos básicos con lo visto hasta ahora. La Constitución calla sobre su elección y duración de mandato, limitándose el artículo 54 a decir que

Una ley orgánica regulará la institución del Defensor del Pueblo, como alto comisionado de las Cortes Generales, designado por éstas para la defensa de los derechos comprendidos en este Título, a cuyo efecto podrá supervisar la actividad de la Administración, dando cuenta a las Cortes Generales.

\footnotetext{
9 En concreto dice así: Los Consejeros de Cuentas serán designados por las Cortes Generales, seis por el Congreso de los Diputados y seis por el Senado, mediante votación por mayoría de tres quintos de cada una de las Cámaras, por un período de nueve años.

${ }^{10}$ Que dice lo siguiente: 1. Antes de los cuatro meses previos a la fecha de expiración de los nombramientos de los Consejeros de cuentas, el Presidente del Tribunal, o quien legalmente le sustituya, solicitara de los Presidentes del Congreso de los Diputados y del Senado la iniciación del procedimiento que haya de conducir a la elección de los mismos. ... 3. Los Consejeros de cuentas continuarán en el ejercicio de sus funciones hasta que hayan tomado posesión quienes hubieren de sucederles.
} 
Y es la Ley orgánica 3/1981, de 3 de abril, del Defensor del Pueblo, la que disciplina su elección por tres quintos del Congreso y Senado y prevé un mandato quinquenal ${ }^{11}$.

Por su parte, el artículo 5 de la misma ley, tras recordar que una de las causas de cese es la expiración del plazo de su nombramiento, dispone en su apartado 3 que

Vacante el cargo se iniciará el procedimiento para el nombramiento de nuevo Defensor del Pueblo en plazo no superior a un mes.

En principio lo anterior debía significar —en el caso de agotamiento del mandato quinquenal — que una prórroga sería viable durante el mes siguiente a este hecho ${ }^{12}$. Pero ni siquiera esta moderada prórroga se hace posible pues el apartado 4 viene a disponer una sustitución interina del titular del órgano por sus adjuntos ${ }^{13}$. Este es un rasgo diferencial, ya que hace de todo punto imposible una prórroga o extensión del mandato del Defensor del Pueblo. Pero entonces resurge una cuestión análoga sobre la duración de esta sustitución, pues tratándose de algo expresamente calificado como interino parece que no puede extenderse indefinidamente. También aquí el espíritu de la Constitución y de la ley resulta opuesto a una vacante prolongada en la titularidad del órgano, pues le incapacitaría para desplegar plenamente sus funciones. Ese espíritu demanda una renovación en un plazo prudencial. Sin embargo, en este caso cuesta más calificar la situación de ilegal o inconstitucional, pues no hay prolongación del mandato quinquenal.

${ }^{11}$ Concretamente el artículo 2 afirma: 1 El Defensor del Pueblo será elegido por las Cortes Generales para un periodo de cinco años ... 4. Propuesto el candidato o candidatos, se convocará en término no inferior a diez días al Pleno del Congreso para que proceda a su elección. Será designado quien obtuviese una votación favorable de las tres quintas partes de los miembros del Congreso y posteriormente, en un plazo máximo de veinte días, fuese ratificado por esta misma mayoría del Senado.

${ }^{12}$ Interpretado literalmente, lo que parece exigir este apartado es que el procedimiento de designación del nuevo Defensor del Pueblo se inicie dentro del mes siguiente, no que concluya. Por tanto, la designación podría aguardar más allá de un mes sin quiebra legal. Sin embargo, en una interpretación finalista esta conclusión no se mantiene, pues la ausencia de término para la designación haría que quedase en nada la previsión del mandato quinquenal.

En sentido parecido, ALBERTO PÉREZ CALVO interpreta el plazo del art. 5.3 LODP como relativo al periodo en que la comisión mixta debe proponer el o los candidatos. Véase 1996, p. 536.

${ }_{13}$ Su texto es el siguiente: En los casos de muerte, cese o incapacidad temporal o definitiva del Defensor del Pueblo, y en tanto no procedan las Cortes Generales a una nueva designación, desempeñarán sus funciones interinamente, en su propio orden, los Adjuntos al Defensor del Pueblo. 


\section{LA PROPUESTA DE SANTAMARÍA PASTOR}

Como se desprende del resumen que incluimos en el anexo, se han producido sensibles retrasos en la designación/elección de los integrantes de estos órganos, con incumplimiento de los mandatos constitucionales y legales, y superándose los límites en que sería justificable una prorogatio. En general tales retrasos se acentúan en los últimos tiempos, agravándose así el problema.

La cuestión a debatir entonces es cómo corregir esta situación, pues ciertamente si la misma resulta inconstitucional o ilegal debiera buscarse pronto y suficiente remedio. A ello se dedican las líneas siguientes.

Recientemente sobre este mismo problema se ha pronunciado Santamaría Pastor en un brillante y sagaz artículo ${ }^{14}$. Podemos resumir su contenido en los siguientes puntos. Por un lado, que la extensión fáctica del periodo por el que son elegidos estos órganos no puede aceptarse visto el espíritu constitucional con el que fueron configurados; por otro, que dicha situación estaría lesionando los principios de temporalidad e independencia del poder, por lo que cuando se producen retrasos manifiestos, como son los comentados, el resultado sería difícilmente compatible con la Constitución. Además añade el administrativista y tal vez aquí reside la parte más sustanciosa de su comentario - la situación creada estaría generando los siguientes efectos perversos: a) una tendencia hacia su retroalimentación, una invitación a su empleo sistemático, al transmitir la sensación de que, pese a todo, el órgano sigue funcionando; b) una deslegitimación del órgano prorrogado y del conjunto del sistema, por su incapacidad para cumplir con sus deberes de renovación; c) una sensación de interinidad para los componentes del órgano en cuestión que les llevaría a una actitud de pasividad e inactividad y d) una invitación a asimilar dicha situación con la del Gobierno en funciones, con el consiguiente abandono de las propias responsabilidades.

El diagnostico anterior nos resulta muy cabal, y confirma nuestra impresión de que no es cuestión baladí el incumplimiento de los plazos.

Sin embargo, hay también algunos puntos con los que discrepamos y esto es lo que pasamos a debatir.

A juicio de Santamaría Pastor, la prorogatio de hecho contraviene el principio implícito constitucional de temporalidad del poder, del que a su vez derivaría el de independencia ${ }^{15}$.

Que se contraviene el principio de temporalidad resulta indiscutible. Incluso más que de principio habría que hablar de mandato estricto, mandato cons-

\footnotetext{
${ }^{14}$ Véase JUAN ALFONSO SANTAMARÍA PASTOR 2008, p. 11-26.

15 Véase 2008, p. 16.
} 
titucional en el caso del Tribunal Constitucional y legal en el caso del CGPJ, del Tribunal de Cuentas y hasta del Defensor del Pueblo. Pues se impone un periodo de 9 años en el primer caso, 5 en el segundo, 9 en el tercero y 5 en el cuarto.

En cambio, a nuestro juicio, es dudoso que la prolongación ilegal se traduzca en una merma de la independencia. Tiene unas consecuencias nocivas, como las que expone este autor y antes recogimos, pero no esa disminución de independencia. Es más la independencia de los órganos constitucionales tiende a estar reñida con la temporalidad. Podría decirse que duración e independencia se presentan en modo inversamente proporcional: a mayor brevedad del periodo menor independencia y viceversa. La razón es evidente: el que dispone de un mandato prolongado o, especialmente, vitalicio se sentirá más fuerte, menos inclinado a compensar o agradecer la promoción recibida en su momento, entre otras cosas por que con el paso del tiempo pueden hasta haber desaparecido sus benefactores. El ejemplo del Tribunal Supremo de los EE UU es paradigmático en este sentido, como también el de nuestros tribunales de justicia ordinarios.

Bien es verdad, como afirma el autor mencionado, que el constituyente español se cuidó de establecer unos periodos distintos y en todo caso más largos que los del mandato parlamentario, para desligar la composición de estos órganos de los resultados electorales y con ello favorecer su distanciamiento.

Pero la caducidad del mandato y a veces su brevedad (como en el CGPJ o en el Defensor del Pueblo) llevan a la conclusión de que este propósito no se desarrolló plenamente, que se dejo abierto a la influencia política o partidista. Podría afirmarse que la nota de independencia se aceptó con menguada convicción y no poca contradicción. De hecho este mismo autor reconoce que «el constituyente conocía a la perfección que, siendo los miembros de estos órganos designados por otros de composición estrictamente política, la tendencia a designar a personas afines era inevitable».

Por tanto, al establecer esa temporalidad de los órganos constitucionales nuestro sistema optó por una mayor o menor permeabilidad política, legítima sin duda, pero que impide hablar del principio de independencia en sentido riguroso y de su conculcación cuando se sobrepasan los periodos de mandato ${ }^{16}$.

Lo que sí sufre grave quebranto y merece el consiguiente reproche es la vulneración de claros mandatos constitucionales, como son los relativos a la du-

16 Señala HORST SÄCKER que el Tribunal Constitucional, por sus propias características y funciones no puede ser un órgano jurisdiccional más, sino un órgano con una dimensión política. Sin embargo, añade esto no puede significar una politización en sentido negativo, un politización partidista de sus componentes. Véase 1981, p. 32 y s. 
ración de órganos constitucionales mediante la prorogatio de la que venimos hablando. No se hiere el principio de independencia pero sí el de legalidad o constitucionalidad (artículo 9 de la ley fundamental), que, como recientemente recuerda Albrecht Weber, es elemento capital, sine qua non del Estado de Derecho $^{17}$.

Resulta ciertamente inquietante que el legislador, llamado a dar ejemplo en el cumplimiento de la legalidad, se permita infracciones tan evidentes de la Constitución y leyes básicas. Es una actuación deslegitimadora del Parlamento y, siendo éste pieza clave del edificio constitucional, su deslegitimación corre el riesgo de extenderse a todo el edificio. A nuestro juicio aquí reside la trascendencia del yerro comentado, más que en el olvido de principios más o menos imprecisos sobre la independencia de estos órganos.

Tras su resuelta denuncia, el profesor Santamaría Pastor parece proponer como solución la supresión de la prorogatio ${ }^{18}$. Suponemos que se referirá a su supresión expresa, pues de todo lo que venimos comentando se deduce que está implícitamente prohibida por la Constitución y leyes de desarrollo ${ }^{19}$, como él también acepta. No se puede suprimir algo que está de por sí excluido.

Esta propuesta coincide en términos generales con la que después recogemos como solución italiana, por lo que reservamos el comentario para cuando enjuiciemos esta última.

\section{DOS REFERENCIAS: LOS CASOS DE ITALIA Y ALEMANIA}

En Italia se produce la misma situación con los magistrados del Tribunal Constitucional, elegidos por mayoría de tres quintos del Parlamento en sesión conjunta. Ahora bien la situación no es tan turbadora como en España. Primero porque las Cámaras sólo eligen a un tercio del Tribunal Constitucional y no a dos tercios, por lo que el posible retraso afecta en menor grado a la continuidad del mismo ${ }^{20}$. Y segundo porque si el Parlamento se retrasa en la elección, los magistrados cuyo mandato ha expirado cesan en todo caso, sin prórroga de sus fun-

17 Véase ALBRECHT WEBER 2008, p. 48 y ss.

18 Véase La prorrogatio ..., ob. cit., p. 24 y ss.

19 Con la salvedad advertida para el Defensor del Pueblo.

${ }^{20}$ Un segundo tercio corresponde al presidente de la República y el tercero a los tribunales superiores ordinario y administrativo. Concretamente el párrafo primero del artículo 135 dispone: La Corte costituzionale è composta di quindici giudici nominati per un terzo dal Presidente della Repubblica, per un terzo dal Parlamento in seduta comune e per un terzo dalle supreme magistrature ordinaria ed amministrative. 
ciones, por disponerlo así el artículo 135 párrafo cuarto de la Constitución: al concluir el mandato el juez constitucional cesa en el cargo y en el ejercicio de las funciones $^{21}$. De este modo no se produce la duda sobre la constitucionalidad de la prorogatio de hecho.

En todo caso, el precedente italiano de mayorías hiper reforzadas y retrasos en la elección parlamentaria parece confirmar que es esta exigencia de mayorías la que vicia la situación y constituye la raíz del problema ${ }^{22}$.

Algo parecido ha ocurrido en Alemania. Como es sabido, el artículo 94 de la ley Fundamental de Bonn se remite en cuanto a la composición y procedimientos del Tribunal Federal Constitucional a una ley posterior, la Bundesverfassungsgerichtsgesetz. Pues bien esta dispone que el Bundestag - a través de una comisión electoral especial- elija ocho magistrados y el Bundesrat o Consejo Federal otros ocho, debiendo en ambos casos recaer tres de estos nombramientos en jueces de los tribunales federales superiores. Estas elecciones deben tener lugar tres meses antes de la expiración del mandato de los magistrados salientes o, en caso de imposibilidad por disolución del Bundestag, en el mes siguiente a su constitución.

Según la redacción original del artículo 6 de la Ley, la elección de ocho magistrados correspondientes al Bundestag se efectuaba no por el pleno sino por una comisión elegida por el mismo mediante representación proporcional del tipo d'Hondt. De este modo el órgano elector reflejaba la fuerza numérica de cada grupo parlamentario. Además para la elección se exigía una mayoría de nueve votos sobre los doce miembros de la dicha comisión, equivalente nada menos que a sus tres cuartas partes. Esta última exigencia condujo a una distorsión de la proporcionalidad y a ciertos retrasos en la elección. Por eso fue reformada la Bundesverfassungsgerichtsgesetz en 1956 para reducir la mayoría requerida, pasando de nueve a ocho de sus doce miembros, esto es, a sus dos tercios $^{23}$, todavía superior a los tres quintos de nuestras Cámaras. El Bundesrat siempre ha elegido por dos tercios de sus componentes en pleno.

${ }^{21}$ En el original: Alla scadenza del termine il giudice costituzionale cessa dalla carica e dall'esercizio delle funzioni. Esta norma fue introducida en la reforma constitucional de 22 de noviembre de 1997. El silencio anterior sobre este aspecto facilitaba la admisión de la prorogatio. Véase sobre el sistema anterior: GIUSTINO D’ORAZIO 1966, p. 502 y s.

En general sobre la situación del Tribunal Constitucional italiano puede verse http://www.cortecostituzionale.it/istituzione/lacorte/cosaelacorte/pag 05.asp

${ }^{22}$ Así también lo reconoce CRISTINA PAUNER CHULVI 2003 p. 182 y s. Añade que el problema se produce por la falta de sanción en caso de incumplimiento y que no hay solución fácil.

${ }^{23}$ Para lo que sigue son de utilidad los datos proporcionados por RICHARD LEY 1991, pp. 420 ss. 
Asimismo, en esa reforma se dispuso que en caso de transcurrir el plazo de elección sin que ésta se hubiese efectuado, el miembro más antiguo de la comisión electoral y el presidente del Consejo Federal o Bundesrat debían dirigirse sin demora al Tribunal Constitucional para que este proponga por mayoría simple a candidatos a magistrados, tres si se trata de cubrir una vacante y el doble de las vacantes cuando estas sean varias ${ }^{24}$. Es una medida sugerente pues puede ayudar a desbloquear una situación de desacuerdo entre los partidos parlamentarios. De la misma se ha hecho un uso moderado: en ocho casos se instó esta respuesta del Tribunal Constitucional y sólo en cuatro este hizo uso de su facultad.

Por lo demás, siempre siguiendo a R. Ley, los retrasos en la renovación del Tribunal Federal Constitucional alemán han sido de mucha menor envergadura que en España: desde 1951 hasta 1991, año de la aparición de su estudio, reseña (anexo) 99 elecciones individuales de magistrados. Pues bien en 18 de estos casos se dio un retraso de un mes, en 11 de hasta dos meses, en 12 hasta seis meses, en 4 hasta doce meses y en 1 más de un año ${ }^{25}$.

Como puede verse, la situación es mejor que en España. Seguramente estos cortafuegos y un mayor sentido institucional explican la diferencia.

\section{ALGUNAS SOLUCIONES Y SUS LIMITACIONES}

Pasamos ahora a exponer las soluciones que se ofrecen para solucionar o paliar tan serio problema. Y lo haremos yendo de las acaso más superficiales o, si se quiere, más practicables a las más rigurosas o profundas.

- Una primera solución sería importar el modelo italiano, de exclusión expresa de la prórroga, imponiendo el cese ope legis del magistrado o consejero al transcurrir su mandato. Ello exigiría la reforma de las leyes orgánicas que regu-

${ }^{24}$ Concretamente el artículo 7, en lo que aquí interesa, establece: (1) Kommt innerhalb von zwei Monaten nach dem Ablauf der Amtszeit oder dem vorzeitigen Ausscheiden eines Richters die Wahl eines Nachfolgers auf Grund der Vorschriften des \$ 6 nicht zustande, so hat das älteste Mitglied des Wablausschusses unverzüglich das Bundesverfassungsgericht ufzufordern, Vorschläge für die Wahl zu machen. (2) Das Plenum des Bundesverfassungsgerichts beschließt mit einfacher Mehrheit, wer zur Wahl als Richter vorgeschlagen wird. Ist nur ein Richter zu wählen, so hat das Bundesverfassungsgericht drei Personen vorzuschlagen; sind gleichzeitig mehrere Richter zu wählen, so hat das Bundesverfassungsgericht doppelt so viele Personen vorzuschlagen, als Richter zu wählen sind. $\$ 16$ Abs. 2 gilt entsprechend. (3) Ist der Richter vom Bundesrat zu wählen, so gelten die Absätze 1 und 2 mit der Maßgabe, daß an die Stelle des ältesten Mitglieds des Wablausschusses der Präsident des Bundesrates oder sein Stellvertreter tritt.

25 Véase LEY 1991, pp. 437-438 y 443 y ss. 
lan estos órganos modificando el inciso que da cobertura aparente a los retrasos. Esto es, se sustituiría la cláusula que admite el mantenimiento en funciones por una que dijese que al concluir el mandato se cesa en el cargo y en las funciones respectivas. También podría incorporarse a la Constitución, y hasta sería la solución óptima, pero sin que pueda decirse que sea imprescindible pues esa regulación actual que posibilita las enormes demoras consta en leyes orgánicas, sin que nadie hasta ahora la haya objetado por insuficiencia de rango.

Esta solución a la italiana tiene la ventaja de evitar la reforma de la Constitución, sin duda más problemática que la legal, como luego se expondrá.

Pero también son varios sus inconvenientes. Por un lado, la previsión actual de mantenimiento en funciones es razonable cuando se atempera a un uso prudente, por lo que su desaparición integral podría originar otros inconvenientes, como la de desatender los retrasos causados por coincidir con la disolución de las cámaras y nuevas elecciones. De otra parte, no es seguro que una exclusión expresa de la prolongación del mandato vaya a recibir más respeto que la exclusión tácita ya vigente. Visto que las fuerzas políticas no han sentido grave reparo en olvidar los terminantes mandatos constitucionales y legales, es problemático que su recogimiento expreso vaya a inducir una mayor diligencia en las mismas.

A lo que se añadiría el problema práctico de convencer a dichas fuerzas políticas de la necesidad de introducir una cláusula que puede privarles de un régimen con rentabilidad partidista. En esto se asemeja a lo que después comentaremos sobre la solución más profunda. Nos remitimos pues a lo allá expuesto.

Pero la limitación más grave que tiene la solución italiana es su desajuste con otros extremos del sistema español. Pues en el país transalpino la prolongación de las vacantes producida por el transcurso del plazo afecta a tan sólo una tercera parte del Tribunal Constitucional, las correspondientes a la elección parlamentaria. Con lo cual no parece que semejante situación pueda afectar seriamente al quórum de funcionamiento del órgano. En cambio, en España el cese ipso iure por el agotamiento del mandato, sin que paralelamente se elija a los sucesores, afectaría cuando menos a un tercio del Tribunal Constitucional y a la totalidad del CGPJ y del Tribunal de Cuentas. Con ello se impediría o se dificultaría en extremo la existencia de ese quórum de funcionamiento. Así el artículo 14 de la LOTC lo fija en dos tercios de los magistrados. Bastaría entonces que una cámara se retrasase en la nueva elección, unido a una baja por fallecimiento, enfermedad u otra causa, para que el Tribunal Constitucional no pudiese funcionar. En el caso del CGPJ y del Tribunal de Cuentas los efectos serían de vacío absoluto de la institución ${ }^{26}$.

${ }^{26}$ En el mismo sentido crítico se manifiesta LUIS AGUIAR DE LUQUE 2009, p. 92 y s. 
De otra parte, debe tenerse en cuenta que en Italia no se practica el sistema de elección por bloques de los magistrados constitucionales, sino el de elección según se van produciendo los ceses por alcanzar el mandato de nueve años. Por eso las renovaciones son parciales y graduales, lo que atempera el impacto negativo de un posible retraso en la elección del sucesor ${ }^{27}$. En cambio en España se ha optado por la renovación por bloques del Tribunal Constitucional, lo que favorecería en extremo la emergencia de una situación como la descrita ${ }^{28}$.

- Una variante de la solución anterior sería abandonar la renovación por bloques e implantar la renovación singular de las vacantes, una a una, según se fuesen produciendo. El plazo de nueve años se computaría desde la designación o toma de posesión de cada magistrado y, siendo estas distintas en cada caso, la renovación acontecería también en fechas distintas. Indudablemente esta modificación podría facilitar mucho las cosas. Pues, como luego se indica, el problema fundamental estriba en fijar la cuota de «designables» que corresponde a cada partido. La discrepancia entre grupos parlamentarios se produce por la distinta interpretación del número correspondiente a cada uno de ellos. Ciertamente, puede no desaparecer si se trata de elegir o designar a uno solo, pero lo más probable es que disminuiría considerablemente. Pues ya no se discutiría sobre cuotas sino sobre la idoneidad del candidato postulado.

Pero también implicaría una reforma constitucional, como es la del último inciso del artículo 159.3 (Los miembros del Tribunal Constitucional ... se renovarán por terceras partes cada tres años), con las dificultades consiguientes.

Pero, sobre todo, el gran inconveniente es que implica un cambio radical de modelo: del sistema europeo de designaciones parlamentarias plurales, con la casi consiguiente consecuencia de distribución partidista, se pasaría al sistema americano donde el Congreso solo interviene para ratificar la designación presidencial. Frente a la pluralidad de opciones actual se trataría meramente de confirmar o rechazar al candidato de la mayoría, léase candidato gubernamental. De una función electiva, las Cámaras se quedarían en una de control sobre ese candidato. Pues resulta indudable que tratándose de la provisión de un solo puesto, será la mayoría parlamentaria la que dispondrá de la iniciativa al respecto. No es previsible que se pudiesen negociar conjuntos de nombramientos, dado que bien

27 Véase al respecto: http://www.cortecostituzionale.it/istituzione/lacorte/cosaelacorte/ pag 04.asp

${ }^{28}$ Afirma EDUARDO ESPÍN TEMPLADO que a la vista de la contradicción interna del artículo 159.3 de la Constitución, el Tribunal Constitucional ha optado por la interpretación de la renovación por tercios y no al cumplir cada magistrado los nueve años de mandato. Véase 2001, p. 301 y ss.

(C) UNED. Revista de Derecho Político 
podrían acontecer en fechas distanciadas y que esa es precisamente la finalidad.

Por tanto, aunque la medida en sí teóricamente podría resultar positiva, en la realidad afectaría a intereses muy consolidados, lo que hace descartar su viabilidad política. Las fuerzas políticas que en mayor o menor medida participan en la distribución de puestos verían mermadas sus facultades y es de suponer que se opongan a cambio tan drástico.

De otra parte, y aunque esto es ya una cuestión relativamente menor, habría que regular el dies a quo para el cómputo de los nueve años del mandato, haciendo que el mismo variase en el caso de los actuales integrantes de la institución, para así garantizar que la futura renovación acontezca en fechas diversas, al menos para los elegibles por las Cámaras.

Además, la dificultad aumentaría enormemente en el caso del CGPJ y del Tribunal de Cuentas. El escalonamiento de las renovaciones se hace mucho más arduo cuando se trata de elegir a veinte y doce miembros respectivamente. Sobre todo en el primer caso obligaría a intervenciones parlamentarias casi continuas, si es que se mantiene el mandato de cinco años. Con lo cual lo más probable es no se conseguiría desprenderse del actual modelo de renovación por cuotas.

— Una tercera solución podría ser disponer que la elección por las cámaras se efectuase por un sistema de representación proporcional. Se trataría de una previsión en la línea de lo que establece el artículo 69.5 de la Constitución ${ }^{29}$ para la elección de senadores por las Asambleas legislativas de las Comunidades Autónomas: cada grupo vería asegurado un cupo de electos más o menos equivalente a su fuerza numérica. De este modo se impulsaría una composición plural de los órganos en cuestión, pero sin tener que superar barreras paralizantes.

En apoyo de esta solución puede tenerse en cuenta lo observado en Alemania. Como ya vimos, el Bundestag elige una comisión electoral de doce diputados mediante un sistema de representación proporcional tipo d'Hondt ${ }^{30}$. Esta

29 Que dice: Las Comunidades Autónomas designarán además un Senador y otro más por cada millón de habitantes de su respectivo territorio. La designación corresponderá a la Asamblea legislativa o, en su defecto, al órgano colegiado superior de la Comunidad Autónoma, de acuerdo con lo que establezcan los Estatutos, que asegurarán, en todo caso, la adecuada representación proporcional.

${ }^{30}$ Concretamente el artículo 6 de la Ley del Tribunal Constitucional Federal establece: (1) Die vom Bundestag zu berufenden Richter werden in indirekter Wahl gewählt. (2) Der Bundestag wählt nach den Regeln der Verhältniswahl einen Wahlausschuß für die Richter des Bundesverfassungsgerichts, der aus zwölf Mitgliedern des Bundestages besteht. Jede Fraktion kann einen Vorschlag einbringen. Aus den Summen der für jeden Vorschlag abgegebenen Stimmen wird nach dem Höchstzahlverfahren (d'Hondt) die Zahl der aufjeden Vorschlag gewählten Mitglieder errechnet. Gewählt sind die Mitglieder in der Reihenfolge, in der ihr Name auf dem Vorschlag erscheint. Scheidet ein Mitglied 
comisión elige en un segundo momento — sin intervención posterior del pleno- a los ocho magistrados correspondientes. Aunque cada uno de ellos debe obtener al menos ocho votos, por tanto una mayoría agravada, esa composición favorece que esa proporcionalidad se refleje también en la selección de los escogidos $^{31}$. Nada se dice en cambio sobre elección proporcional en los ocho magistrados que corresponden al Bundesrat, limitándose el artículo 7 a exigir una mayoría de dos tercios.

Las Constituciones de algunos Länder se inclinan también por una solución de este tipo. Concretamente el artículo 112 de la de Brandenburgo afirma que los magistrados constitucionales son elegidos sin debate por la Dieta para diez años y que se procurará en la elección que las propuestas representen adecuadamente a todas las fuerzas políticas del Estado ${ }^{32}$. El artículo 130 de la Constitución de Hesse señala que seis de los once miembros del Tribunal Superior del Estado son elegidos por la Asamblea conforme a los principios de representación proporcional ${ }^{33}$. Finalmente, el artículo 139 de la Constitución de Bremen dispone que la elección de los miembros del Tribunal Superior del Estado se haga teniendo en cuenta en lo posible la fuerza numérica de los grupos parlamenta$\operatorname{rios}^{34}$.

des Wahlausschusses aus oder ist es verhindert, so wird es durch das nächste auf der gleichen Liste vorgeschlagene Mitglied ersetzt. ...(5) Zum Richter ist gewählt, wer mindestens acht Stimmen auf sich vereinigt. Por su parte, el artículo 7 exige una mayoría de dos tercios para la elección de los jueces que corresponde al Bundesrat: Die vom Bundesrat zu berufenden Richter werden mit zwei Dritteln der Stimmen des Bundesrates gewählt.

31 Así lo afirman KLAUS SCHLAICH 1991, p. 31 y LEY 1991, p. 435.

$32 \mathrm{Su}$ apartado 4 afirma: Los magistrados constitucionales son elegidos sin debate por la Dieta para diez años. Se procurará en la elección que las propuestas representen adecuadamente a todas las fuerzas politicas del Estado. No podrá haber reelección. Previamente a la elección se celebrará una audiencia en una de las comisiones de la Dieta escogida por ella con este fin y resultarán elegidos los candidatos que hayan obtenido en votación secreta los votos de una mayoría de dos tercios de los miembros de la Dieta..

33 Su apartado 1 dice: El Tribunal Superior del Estado estará compuesto de 11 miembros, cinco de ellos jueces de carrera y seis elegidos por la Dieta conforme a los principios de la representación proporcional entre personas que no sean miembros de ella. Se nombrará asimismo un acusador público.

${ }^{34}$ Su texto es el siguiente: Se instituye un Tribunal Superior del Estado. El Tribunal Superior del Estado estará compuesto, si no se constituye juntamente con otros Estados alemanes, por el Presidente del Tribunal Administrativo Superior o su sustituto, así como de seis miembros electivos, de los cuales dos deben ser jueces de Bremen expertos en derecho. Los miembros electivos serán elegidos por la Asamblea de los Ciudadanos inmediatamente después de su primera sesión plenaria para toda la legislatura y permanecerán en el cargo hasta que la Asamblea siguiente efectúe la nueva elección. En la elección se deberán tomar en cuenta en lo posible los efectivos de los grupos parlamentarios. Los miembros electivos no podrán ser miembros del Senado ni de la Asamblea. Se permite la reelección. 
De hecho, la aplicación de este mismo sistema para los senadores autonómicos al amparo del artículo 69.5 de la Constitución revela que el peligro de bloqueo disminuye en medida muy significativa.

Pero también esta fórmula se enfrenta a serios inconvenientes. Para empezar, la proporcionalidad obtenida puede ser satisfactoria en el caso del CGPJ y del Tribunal de Cuentas, por ser bastantes los puestos a proveer. En cambio, nunca será muy elevada en la elección del Tribunal Constitucional, habida cuenta de que la provisión de cuatro magistraturas no se presta a una distribución propiamente tal.

Todavía más importante es que para que funcionase correctamente sería necesario suprimir la exigencia de mayorías reforzadas. Bien es verdad que en Alemania se combinan las dos exigencias de proporcionalidad y mayoría reforzada, pero parece cierto que si se mantiene la segunda siempre habrá un riesgo de que un partido político se aproveche de la misma, ejerciendo una suerte de veto paralizante. De hecho en Alemania también se han dado retrasos, aunque en menor cantidad y duración. Por tanto, el sistema de proporcionalidad solo parece garantizar el cumplimiento de los plazos si funciona desligado de mayorías reforzadas.

Además, esta fórmula tiene en su contra el destacar en exceso la afinidad partidaria de cada uno de los elegidos, mermando así su deseable imagen de independencia. Se difuminaría la ficción nada superflua que hace que todos los elegidos lo sean institucionalmente, sin marcas de grupos políticos.

Pero esta consecuencia tampoco debería escandalizar en exceso porque lo que se persigue es precisamente la distribución plural y la imposibilidad de un abuso por la mayoría. Además, no es muy distinto a lo que ya ocurre, por lo que tampoco podría ser criticado desde este punto de vista. Permitiría así una elección equilibrada, pero sin el inconveniente de incumplir los plazos constitucionales y legales de renovación.

En todo caso, se mantengan o no las mayorías reforzadas de tres quintos, es indudable que por tratarse de un requisito materialmente constitucional el mismo tendría que constar en la Constitución. Se trata de una exigencia básica, estructural, que no admite otro rango que el de la ley fundamental. En concreto habría que reformar el artículo 123.3 sobre el CGPJ y el 159.1 sobre el Tribunal Constitucional. Y esto abriría todas las dificultades jurídicas y políticas a las que después nos referiremos. En el caso del Tribunal de Cuentas y el Defensor del Pueblo obviamente bastaría la modificación de sus respectivas leyes institutivas.

- Una cuarta solución podría consistir también en introducir la regulación alemana ya aludida de que en caso de transcurrir el plazo de elección sin que ésta se haya efectuado, el miembro más antiguo de la comisión electoral del Bun- 
destag y el presidente del Consejo Federal debían dirigirse sin demora al Tribunal Constitucional para que este proponga por mayoría simple a candidatos a magistrados, tres si se trata de cubrir una vacante y el doble de las vacantes cuando estas sean varias ${ }^{35}$. Esto supondría obligar a los presidentes de las dos Cámaras a poner en conocimiento del Tribunal Constitucional el transcurso infructuoso de los plazos de elección, de tal modo que el segundo pudiese formular una propuesta en un tiempo determinado.

Esta última posibilidad tiene la ventaja de actuar como una señal de alarma contra las fuerzas parlamentarias, obligándolas a ponerse de acuerdo so pena de incurrir en esta suerte de sanción moral y pública. Pero también ofrece serios reparos. Primero porque traslada una iniciativa sumamente delicada al órgano que debe ser renovado, una iniciativa no parangonable con sus funciones oficiales sino con opciones o preferencias personales, con el consiguiente riesgo de que el mismo se convierta en objeto de presión por diversos sectores e intereses. En una palabra que se politice su actuación. Segundo porque tampoco asegura el llegar a puerto a tiempo. Esto es, cabe tanto que las Cámaras posterguen la notificación al concluir el plazo de renovación como que el propio órgano emplazado (Tribunal Constitucional, GGPJ o Tribunal de Cuentas) se demore en exceso en seleccionar a los propuestos, y también que de nuevo las Cámaras incidan en la misma omisión al recibir las candidaturas propuestas. Pero desde luego, más vale esta fórmula que la carencia de todo impulso de contrapeso o rectificación.

\section{LA RAÍZ DEL PROBLEMA Y LA SOLUCIÓN COHERENTE}

A nuestro juicio, la raíz del problema, lo que corrompe las previsiones constitucionales sobre la duración del mandato no es una supuesta perversidad de las fuerzas políticas, sino el régimen de elección de los miembros de estos órganos constitucionales.

De por sí, la elección parlamentaria de órganos colegiados favorece la disputa sobre el número que deba corresponder a cada fuerza política en el seno de las cámaras, especialmente cuando el sistema se inspira, como el nuestro, en el principio de representación proporcional, que induce una dialéctica de proporcionalidad en las designaciones y acuerdos posteriores. Así la STC 141/1990, f.j. 6, afirmó que esta proporcionalidad electoral se tiene que reflejar en los órganos internos de las Cámaras. Esto provoca un tira y afloja sobre la forma de distri-

35 Véase artículo 7 ya citado de la Bundesverfassungsgerichtsgesetz. 
buir las vacantes disponibles de otros órganos entre las fuerzas que participan en su elección.

Si a lo anterior se añaden las fortísimas mayorías exigidas, como la de tres quintos de los componentes de las Cámaras, todo está servido para que los nombramientos parlamentarios no se produzcan dentro de los plazos establecidos.

Para empezar, tales mayorías se compadecen muy poco con unas votaciones que se tienen que reiterar con cadencias más bien breves ${ }^{36}$. Semejantes mayorías son propias de votaciones extraordinarias, que afectan a los fundamentos del Estado y que por eso se producen ocasionalmente, como las de reforma constitucional (artículo 167). La STC 179/1989, f.j. 7, aun admitiendo su licitud, reconoce que el principio debe ser el de la mayoría simple:

Es cierto que, como señala el Abogado del Estado, el carácter democrático del Estado Español que proclama el art. 1 de la Constitución implica que ha de ser el principio de las mayorías el que regule la actuación de los órganos parlamentarios (estatales o autonómicos) en el proceso de toma de decisiones; pero ello no implica que tal mayoría haya de ser forzosamente la mayoría simple. Aun cuando efectivamente sea esta la norma generalmente seguida en los procedimientos parlamentarios, no cabe excluir que en algunos de ellos, en aras de obtener un mayor consenso, para proteger más eficazmente los derechos e intereses de las minorías, o con otro objeto razonable, se exijan mayorías cualificadas.

La razón invocada de este requisito es favorecer la independencia del órgano constitucional, impidiendo que la fuerza política mayoritaria en el Parlamento se reserve todos los nombramientos, pues resulta prácticamente imposible que un solo partido pueda alcanzar una mayoría de tres quintos en las dos Cámaras, como demuestra la experiencia. Con ese trasfondo, se aduce que la única forma de lograr una composición suprapartidista es la de forzar un amplio acuerdo entre mayoría y oposición a través de un requisito como el comentado. Así se obtendría un perfil equilibrado y plural en la composición de estos órganos ${ }^{37}$.

Sin embargo, la realidad ha venido a confirmar el peligro latente de este sistema que ya denunciamos hace bastantes años ${ }^{38}$, esto es, que los órganos cons-

${ }^{36}$ Cada tres años se produce la renovación parcial del Tribunal Constitucional; cada cinco la integral del CGPJ y del Defensor del Pueblo. La única excepción más dilatada es la del Tribunal de Cuentas con 9 años.

37 Una amplia defensa de este argumento, con referencias a autores españoles y extranjeros, se encuentra en FRANCISCO FERNÁNDEZ SEGADO 1999, p. 96 y s.

38 FERNANDO SANTAOLALLA LÓPEZ 1984 p. 366. Allí decíamos que «semejante requisito, establecido con el laudable propósito de de asegurar una convergencia muy amplia en tor- 
titucionales se queden sin la renovación que exige la Constitución por la imposibilidad de alcanzar una mayoría tan amplia ${ }^{39}$.

Pues, como hemos indicado, no hay un partido político que por si solo alcance esta mayoría de tres quintos. Entonces la viabilidad de la votación pasa por pactar con otros partidos, incluidos los de la oposición, que de esta forma se ven sumamente reforzados, hasta el punto de disponer de una facultad de veto sobre la composición del órgano de que se trate ${ }^{40}$. Estos partidos, sabedores de que sus votos son imprescindibles, pueden oponerse a los candidatos de la mayoría, exigir una cuota en los nombramientos para personas afines, incluso mayor que la que correspondería en pura proporcionalidad, retrasar cuando no interese la renovación, etcétera. Tampoco pueden excluirse maniobras retorcidas de una mayoría a la que interesa mantener la composición actual de estos órganos. En definitiva, efectos perversos, opuestos a los que teóricamente fundamentan el sistema. Más que lograr candidaturas de consenso, suprapartidistas, de personalidades independientes, el sistema ha derivado en un reparto de las vacantes por cuotas de partido ${ }^{41}$. El consenso se construye no sobre el conjunto de los candidatos propuestos sino sobre la adjudicación de cuotas, que luego cada partido administra con amplia discreción. La misma aspiración y el mismo resultado de distribución por cuotas han tenido lugar en Alemania ${ }^{42}$, lo que parece confirmar que el sistema en sus resultados prácticos se aleja de sus postulados teóricos.

Desde luego no decimos que la exigencia de mayorías de tres quintos determine necesariamente este panorama, pero sí que lo favorece en altísimo grado, como muestran los abundantes antecedentes ${ }^{43}$.

no a los elegidos, de tal modo que éstos no se deban a una única fuerza política, comporta el riesgo de que estas elecciones no se verifiquen ante la imposibilidad de superar una barrera tan alta de votos ...".

39 La experiencia acumulada sobre la elección de los magistrados del Tribunal Constitucional revela claramente que los retrasos llamativos se producen cuando intervienen las cámaras. En cambio, cuando lo hace el Gobierno esto apenas se da y eso que coincide con la elección de dos magistrados por el CGPJ, que a su vez tiene que hacerlo por mayoría de tres quintos (art. 127.1.b de la LOPJ). Véase al respecto lo recogido en el apartado III de este trabajo.

40 JUAN ALFONSO SANTAMARÍA PASTOR, que también reconoce esta realidad, lo llama efecto de bloqueo. Véase 2008, p. 19.

${ }^{41}$ Así lo reconocen abiertamente EDUARDO ESPÍN TEMPLADO 2001 p. 297 y CRISTINA PAUNER CHOLVI 2003, p. 153 y s.

42 Así lo afirma KLAUS SCHLAICH 1991, p. 31.

43 Podría incluso objetarse de lege ferenda sobre la conveniencia de que sea el Parlamento quien efectúe estas elecciones, siendo como es una institución netamente política y partidista. Tal es lo que se planteaba por ejemplo GUMERSINDO TRUJILLO 1979 p. 155. Semejante plan- 
Si la raíz del problema reside en estas mayorías reforzadas, el remedio ideal debe consistir en su reducción, introduciendo una elección por mayoría relativa o a lo sumo por mayoría absoluta.

Se nos objetará inmediatamente que esto puede conducir al mal opuesto del abuso de la mayoría, que se reservaría en su totalidad el conjunto de los puestos a cubrir. De este modo — se dirá - tendríamos unos órganos constitucionales esencialmente sectarios, obedientes a la mayoría ocasional del Parlamento.

Que este peligro existe resulta indudable. Todo poder, como indicó lord Acton, tiende al abuso, por lo que en modo alguno se puede descartar el acaparamiento de los nombramientos por el partido en el poder cuando la elección tenga que hacerse por mayoría absoluta o simple.

Pero, aun siendo esto así, la cuestión es otra. Lo que se plantea es si queremos que siga perviviendo un régimen de votación que favorece en extremo graves quiebras constitucionales y legales por quien debía ser el paladín de la legalidad. Lo que se plantea no es el posible abuso en los nombramientos, sino el mantenimiento de un principio capital del Estado de Derecho como es el de constitucionalidad y legalidad (artículo 9 de la Constitución). El abuso podrá y deberá ser denunciado, pero nunca resultará tan lesivo constitucionalmente como la infracción pura y dura de normas constitucionales y legales.

De otra parte, ¿estamos tan seguros que una regla como la defendida empeorará las cosas, conduciendo a una gubernamentalización excesiva de estos órganos constitucionales?

Repetimos que el abuso o acaparamiento constituye una amenaza latente y real. Pero tampoco ese desenlace tiene que darse inexorablemente. Acaso podría ser una alternativa a la situación presente, no tan mala como se ha querido ver.

Téngase en cuenta, en primer lugar, que con el sistema de mayoría de tres quintos el partido mayoritario, o sea el Gobierno, después de todos los forcejeos y cesiones que se quiera, suele acabar reservándose la mayoría de los puestos a cubrir, más o menos en proporción al número de escaños de que dispone en la cámara electora. Cierto es que se da entrada a la oposición (a veces sólo al

teamiento no puede asumirse en este comentario, pues lo que persigue es algo mucho más perentorio, como acabar con retrasos tan escandalosos como los producidos recientemente con el CGPJ y el Tribunal Constitucional.

No obstante, ha de reconocerse que la elección parlamentaria tiene un amplio predicamento en el mundo europeo, como demuestran los casos de los tribunales constitucionales de Alemania e Italia. Por tanto no se trata de una extravagancia de la Constitución española. EDUARDO ESPÍN TEMPLADO lo ha defendido afirmando que solo de esta manera se hace posible alcanzar una cierta sintonía entre la orientación de la Nación y la interpretación de la Constitución por el Tribunal Constitucional. Véase 2001, p. 298. 
principal partido de la oposición), pero siempre en menor medida, en modo más o menos proporcional a su fuerza parlamentaria. $\mathrm{O}$ sea que la posibilidad de hacerse con una influencia decisiva en el seno de estos órganos sigue siendo muy clara para la fuerza política mayoritaria. Esto, que se manifiesta en todos los casos, es todavía más notable en el caso del Tribunal Constitucional, merced a la designación de dos vocales directamente por el Gobierno. De este modo, salvo en los casos en que estos órganos tienen que adoptar decisiones por mayorías cualificadas, la mayoría interna afín a la mayoría parlamentaria puede imponer sus criterios. No se ignora el contrapeso que puede suponer esa «oposición» interna, pero sÍ se quiere subrayar que a la postre la diferencia puede no ser tanta como parece a primera vista.

En segundo lugar —y esto es lo más importante- una elección por mayoría no reforzada puede inducir un sentido de responsabilidad en el partido gobernante. Pues sabe que cualquier abuso por su parte será denunciado inmediatamente por la oposición y por los medios de comunicación, erosionando su imagen de cara a las siguientes elecciones. No debe olvidarse que unas de las acusaciones que más pueden desgastar a la mayoría gubernamental son las de prepotencia y sectarismo, por si mismas y porque no pocas veces estas situaciones acaban siendo fuente de corrupciones y desafueros. Los cuales, a su vez, cuestan un precio en popularidad.

Además, todo partido en el poder sabe que lo que haga o deje de hacer será replicado por el que le suceda. Con lo cual puede presumirse que la fórmula que proporciona mucha capacidad de influencia en un momento dado puede traducirse, con el cambio de circunstancias, en ostracismo y marginación para el que la practica. En palabras más llanas, que será pagado con la misma moneda cuando llegue al poder su hoy rival.

Probablemente este frio e interesado cálculo de consecuencias es uno de los factores que más puede contribuir a una cultura de responsabilidad democráti$\mathrm{ca}$, esto es, respetuosa de las previsiones constitucionales y, en concreto, de que hay espacios institucionales de los que no se puede abusar. La mayoría no reforzada, lejos de conducir a los cataclismos con los que muchas veces se la describe, puede hacerlo en pro de un self-restraint parlamentario, que haría consciente a la fuerza o fuerzas políticas mayoritarias de que, por su propio interés, no puede acometer sectariamente estas elecciones, sino institucionalmente, demostrando que los candidatos elegidos son personas con las máximas cualificaciones para ocupar estos órganos. Y mejor, naturalmente, con el consenso de los partidos de la oposición, pero no necesariamente así. Pues lo que no es de recibo es que la búsqueda de ese deseable acuerdo se traduzca en abiertas infracciones de los plazos de la Constitución, como las que ya se han comentado. 
Para confirmar lo anterior nada mejor que las siguientes palabras de Hans Kelsen ${ }^{44}$ :

Una dictadura constante de la mayoría sobre la minoría resulta imposible, porque una minoría privada por completo de influencia renunciaría al fin y al cabo a su intervención, puramente formal y, por consiguiente, inútil e incluso perjudicial en la formación de la voluntad colectiva, despojando así a la mayoría de su carácter de tal. Precisamente en este recurso dispone la minoría de un medio para pesar sobre los acuerdos de la mayoría, sobre todo en una democracia parlamentaria. En efecto, todo el procedimiento parlamentario con su técnica, son sus controversias dialécticas, discursos y réplicas, argumentos y refutaciones, tiende a la consecución de transacciones.

Así en definitiva se cumpliría con la Constitución doblemente: primero con su espíritu, opuesto a una sumisión incondicional de estos órganos a instancias políticas, por lo que debe ser bienvenida una fórmula que estimula una actitud institucional, no sectaria, en el momento de la elección ${ }^{45}$; y, segundo , con su letra, como son las previsiones de renovación temporal, pues con abuso o sin él en los nombramientos, al menos se respetarían los plazos constitucionales y con ello lo que es propio de un Estado de Derecho ${ }^{46}$. De hecho, como reconoció la STC 32/1981, f.j. 2, pertenece a la esencia de la democracia parlamentaria la ocupación por la mayoría de los puestos de dirección política.

El contraste con la situación actual no puede ser más llamativo, pues aquí se juntan dos graves defectos: nombramientos presididos por espíritu de partido y, encima, incumplimiento sonoro de los plazos constitucionales y legales.

${ }^{4}$ HANS KELSEN 1934, p. 85.

45 Esto fue precisamente lo demandado por el Tribunal Constitucional en su famosa STC 108/1986, sobre la elección del CGPJ, f.j 13: Ciertamente, se corre el riesgo de frustrar la finalidad señalada de la Norma constitucional si las Cámaras, a la hora de efectuar sus propuestas, olvidan el objetivo perseguido y, actuando con criterios admisibles en otros terrenos, pero no en éste, atiendan sólo a la división de fuerzas existente en su propio seno y distribuyen los puestos a cubrir entre los distintos partidos, en proporción a la fuerza parlamentaria de éstos. La lógica del Estado de partidos empuja a actuaciones de este género, pero esa misma lógica obliga a mantener al margen de la lucha de partidos ciertos ámbitos de poder y entre ellos, y señaladamente, el Poder Judicial.

46 EDUARDO ESPÍN TEMPLADO pide que se tomen las medidas oportunas para impedir que las controversias partidistas obstaculicen el estricto cumplimiento de la normativa constitucional y legal. Véase 2001, p. 307. 


\section{INCONVENIENTES POSIBLES DE LO DEFENDIDO Y SU VALOR RELATIVO}

Somos conscientes de que nuestra última propuesta tiene dos serios inconvenientes, interconectados, inconvenientes que en mayor o menor medida también son extensibles a las otras soluciones expuestas.

Por un lado, un inconveniente jurídico: la supresión de la mayoría de tres quintos para dejarla en la ordinaria o en la absoluta exigiría la reforma de los artículos 122.3 (relativo al CGPJ) y el 159.1 (relativo al Tribunal Constitucional) de la Constitución. Lo que obligaría a alcanzar la mayoría de tres quintos del artículo 167 , mayoría que precisamente hemos calificado de muy exigente (si bien justificada cuando se trata de enmendar la ley fundamental del Estado).

Lo anterior, unido a la práctica irreformabilidad que ha demostrado nuestra Constitución, sin más alteraciones desde su promulgación que la nimia del artículo 13.2 en 1992, hace presumir que el empeño no va a ser precisamente fácil.

En el caso de la elección de los vocales del Tribunal de Cuentas y del Defensor del Pueblo la dificultad se suaviza notablemente, pues bastaría reformar las leyes orgánicas constitutivas de estos órganos, antes recogidas. Solo se necesitaría un acuerdo de mayoría absoluta (al amparo del artículo 81 de la Constitución). Pero no es descartable en modo alguno que en la práctica se imponga una apelación a la necesidad de consenso para su modificación, lo que determinaría a la postre que el cambio no resultase tan factible como puede parecer a primera vista.

En segundo lugar está el inconveniente político, el de mayor envergadura. Habría que vence el férreo apego de nuestras fuerzas políticas a las mayorías muy reforzadas, por los buenos réditos que parecen obtener en términos estrictos de partido. Ya antes nos hemos referido a los cálculos maquiavélicos que presiden la renovación de estos órganos al amparo de esa exigencia, cálculos que benefician especialmente a los partidos de la oposición, por la sencilla razón de que les brinda una ocasión de ejercer un poder que en otro contexto no tendrían.

De hecho la regla ha hecho escuela y se ha generalizado su aplicación. No sólo son numerosos los cargos que se proveen total o parcialmente mediante elección parlamentaria, sino también la exigencia para los mismos de mayorías muy fuertes. Baste señalar, a título de ejemplo, que la Ley 17/2006, de 5 de Junio, de la Radio y Televisión de Titularidad Estatal, impone una mayoría todavía más reforzada de dos tercios para los puestos de consejeros y presidente de este organismo ${ }^{47}$.

47 Concretamente su artículo 11 dispone: 1. Los miembros del Consejo de Administración serán elegidos por las Cortes Generales, a razón de ocho por el Congreso de los Diputados y cuatro por el Se- 
Este escollo político es el decisivo, pues en la realidad son bastantes las leyes y otras decisiones que se aprueban con mayorías de tres quintos y aun superiores. Por tanto, la exigencia del artículo 167 de la Constitución no es ni mucho menos tan insuperable como puede parecer a primera vista. Lo que altera el trasfondo es que en las elecciones hechas por el Parlamento entran en juego las cuotas de poder o influencia de los distintos partidos. Nadie quier renunciar a esa capacidad de influir. La votación se asume entonces con mucho espíritu de partido y poco institucional.

A pesar de este panorama tan contrapuesto a lo aquí defendido no podemos dejar de proponer la solución que, yendo a la raíz del problema, puede acabar con un vicio tan ruinoso para el Estado de Derecho. Pues, por poner un ejemplo, la obligación del pago puntual de tributos y otros muchos deberes administrativos tenderá a verse como abusiva por los ciudadanos cuando al mismo tiempo contemplan el incorrecto proceder de los órganos que más debían velar por el prestigio del Estado y su derecho.

En todo caso, está claro que para un jurista teórico lo importante no es lo que pueda beneficiar a las fuerzas políticas que nutren el sistema, por muy legítimas e imprescindibles que sean, sino el funcionamiento coherente y justo de este. Por tanto, a pesar de las dificultades de que una propuesta como la anterior salga adelante, no nos resistimos a dejar constancia de nuestro diagnóstico, quizá erróneo pero sin duda sincero.

\section{ANEXO. RENOVACIONES ACAECIDAS DE LOS ÓRGANOS CONSTITUCIONALES}

Incluimos a continuación un resumen de las renovaciones sufridas por los órganos constitucionales, con referencia al cumplimiento de las previsiones constitucionales y legales sobre el particular.

Respecto al CGPJ debemos comenzar recordando que la Ley orgánica 1/1980, reguladora del mismo, entró en vigor el 30 de enero de 1980. A partir

nado, de entre personas de reconocida cualificación y experiencia profesional. ... 3. Los candidatos propuestos, incluyendo los previstos en al apartado anterior, deberán comparecer previamente en audiencia pública en el Congreso y el Senado, en la forma que reglamentariamente se determine, con el fin de que ambas Cámaras puedan informarse de su idoneidad para el cargo. Su elección requerirá una mayoría de dos tercios de la Cámara correspondiente. 4. El Congreso de los Diputados designará, de entre los doce consejeros electos, al que desempeñará el cargo de Presidente de la Corporación RTVE y del Consejo. Tal designación requerirá una mayoría de dos tercios de la Cámara. 
de ese momento comenzaron a transcurrir los plazos previstos para su elección en su disposición transitoria $5^{\mathrm{a}} .1$ :

Antes de transcurridos 15 días de la entrada en vigor de la presente Ley, el Presidente del Tribunal Supremo se dirigirá a los Presidentes de las Cámaras Legislativas y convocará a la Junta Electoral, adoptando cuantas medidas sean precisas para la puesta en marcha del proceso de constitución del primer Consejo General del Poder Judicial. La elección de los 12 miembros de procedencia judicial deberá convocarse dentro del mes siguiente a la constitución de la Junta Electoral, y se celebrará en el plazo máximo de 2 meses desde su convocatoria.

Lo anterior no debía suponer mucho más de tres meses y medio para la constitución del CGPJ desde la publicación de dicha ley. Sin embargo, la elección por las cámaras no se efectuó hasta el 23 de septiembre (Congreso) y 25 de septiembre (Senado) de ese $a n ̃ o^{48}$, lo que apuntaba ya a un cierto retraso.

En cambio, el segundo CGPJ - constituido ya al amparo de la LOPJ 6/1985, de 1 de julio - se eligió el 3 de octubre (Congreso) y 10 de octubre (Senado) de $1985^{49}$, lo que supuso un ajuste prácticamente completo a las previsiones constitucionales.

Un retraso algo mayor, pero en todo caso no preocupante, se produjo con el tercer CGPJ, pues se eligió pocas semanas más tarde de la expiración legal de su predecesor: el 30 de octubre (Congreso) y 6 de noviembre (Senado) de $1990^{50}$.

Fue con el cuarto CGPJ cuando se dio un sensible retraso, claramente contrario al mandato quinquenal de la Constitución: su renovación debió acontecer a finales de octubre o comienzos de noviembre de 1995. Sin embargo, no lo fue hasta ocho meses más tarde: 23 de julio de $1996^{51}$ (Congreso y Senado).

Por su parte, el quinto CGPJ debió resultar elegido cinco años después de esta última fecha y, sin embargo, no lo fue hasta el 30 de octubre de 2001 (Congreso) y 6 de noviembre de 2001 (Senado), consiguientemente con tres meses largos de retraso.

Finalmente, el retraso más llamativo se ha dado con el último CGPJ —el sexto- pues su elección debió tener lugar antes de estas últimas fechas pero de 2006 y, sin embargo, se retrasó hasta el 16 de septiembre de 2008 (Congreso) y 17 de septiembre (Senado), lo que supone un exceso de dos años.

\footnotetext{
48 Véase Diario de Sesiones del Congreso y del Senado de las fechas mencionadas.

${ }^{49}$ Véase Diario de Sesiones del Congreso y del Senado de las fechas mencionadas.

50 Véase Diario de Sesiones del Congreso y del Senado de las fechas mencionadas.

${ }^{51}$ Véase Diario de Sesiones del Congreso y del Senado de la fecha mencionada.
} 
En el caso del Tribunal Constitucional resumimos su historial de renovaciones por bloques o tercios, omitiendo las individuales producidas por fallecimiento, renuncia etcétera.

Hay que partir del plazo establecido por la Disposición transitoria primera de la LOTC para su constitución:

1. Dentro de los tres meses siguientes a la fecha de la entrada en vigor de la presente Ley, el Congreso de los Diputados, el Senado, el Gobierno y el Consejo General del Poder Judicial elevarán al Rey las propuestas de designación de los Magistrados del Tribunal Constitucional. Este plazo se interrumpirá para las Cámaras por el tiempo correspondiente a los períodos intersesiones. 2. El Tribunal se constituirá dentro de los quince días siguientes a la fecha de publicación de los últimos nombramientos, si todas las propuestas se elevasen dentro del mismo período de sesiones. En otro caso se constituirá y comenzará a ejercer sus competencias, en los quince días siguientes, al término del período de sesiones dentro del que se hubiesen efectuado los ocho primeros nombramientos, cualquiera que sea la razón que motive la falta de nombramiento de la totalidad de los Magistrados previstos en el artículo 5 de esta Ley.

El cumplimiento o la conclusión de estos plazos iniciales se asumen aquí como referencia para las futuras renovaciones ${ }^{52}$. El primer plazo mencionado concluía el 23 de febrero de 1980. Y así se interpretó en la práctica, pues diez de los doce magistrados fueron nombrados por sendos reales decretos publicados en el BOE de 22 de febrero de 1980, por tanto dentro del mismo ${ }^{53}$. Se demoró el nombramiento de los dos magistrados correspondientes al CGPJ (BOE de 19 noviembre de 1980), pero ello sin duda fue consecuencia del retraso ya citado en la formación de este último órgano. En todo caso, esa fecha de nombramiento se convertía en dies a quo para futuras elecciones.

La primera renovación parcial, efectuada al amparo de la Disposición transitoria novena de la Constitución ${ }^{54}$, afectó al Congreso de los Diputados. Debía

52 De hecho así se asumió, como se verá, en las primeras renovaciones. No obstante, es cierto que existe una inseguridad sobre el dies a quo, si el del la primera elección o el de la renovación efectiva del tercio correspondiente. Nosotros asumimos aquí la de la primera elección, pues además de parecernos más correcta, la segunda no parece que haga variar sensiblemente las conclusiones a las que se llega. Sobre este tema véase EDUARDO ESPÍN TEMPLADO 2001, p. 302 y s.

53 Las elecciones en el Congreso y el Senado tuvieron lugar bastante antes, el 30 de enero de 1980. Véase Diario de Sesiones del Congreso y del Senado de la fecha mencionada.

54 Que dice: $A$ los tres años de la elección por vez primera de los miembros del Tribunal Constitucional se procederá por sorteo para la designación de un grupo de cuatro miembros de la misma procedencia electiva que haya de cesar y renovarse. A estos solos efectos se entenderán agrupados como miembros de la misma procedencia a los dos designados a propuesta del Gobierno y a los dos que proceden de 
acontecer antes del 23 de febrero de 1983 y, sin embargo, no se produjo hasta el 27 de septiembre de ese año ${ }^{55}$. Por tanto, se demoró siete meses.

La segunda renovación parcial atañó al grupo de magistrados del Gobierno y del CGPJ y se publicó en el BOE de 22 de febrero de 1986, consiguientemente dentro del término fijado por la ley.

La tercera renovación correspondió a los cuatro magistrados elegidos por el Senado y también se hizo dentro del plazo legal, el 8 de febrero de $1989^{56}$.

La siguiente renovación fue la del Congreso de los Diputados y tuvo lugar el 25 de junio de $1992^{57}$, por lo que no se cumplió el plazo establecido, del 23 de febrero de ese año. Resultado: cuatro meses de demora.

La quinta renovación, relativa a los magistrados propuestos por Gobierno y CGPJ, se verificó con un retraso de un mes y medio, al tener lugar el 7 de abril de $1995^{58}$.

Un retraso más significativo, de casi diez meses, se dio con la sexta renovación, atinente al Senado, ya que ocurrió el 14 de diciembre $1998^{59}$, cuando debió ser anterior al 23 de febrero de ese año.

La séptima renovación interesó al Congreso de los Diputados y se produjo con otro retraso de cuatro meses, al tener lugar 30 de octubre de $2001^{60}$.

La última renovación realizada, la octava, fue la propia del Gobierno y CGPJ y tuvo lugar el 8 de junio de $2004^{61}$, con dos meses de demora sobre el calendario teórico. Pero sin duda el retraso más llamativo ha sido el de la renovación correspondiente al Senado, la novena, que debió tener lugar en febrero de 2007 y que está todavía pendiente al escribirse estas líneas (marzo de 2009).

A lo anterior deba añadirse la vacante producida por el fallecimiento del magistrado Roberto García Calvo el 17 de mayo de 2008, y que sigue sin cubrirse diez meses después por el Congreso de los Diputados.

En el caso del Tribunal de Cuentas la secuencia es mucho más sencilla. Debe partirse de la disposición transitoria sexta de la Ley orgánica 2/1982, de 12 de mayo:

\footnotetext{
la formulada por el Consejo General del Poder Judicial. Del mismo modo se procederá transcurridos otros tres años entre los dos grupos no afectados por el sorteo anterior. A partir de entonces se estará a lo establecido en el número 3 del artículo 159.

55 Véase Diario de Sesiones del Congreso de esa fecha y BOE de 25 de octubre de 2003.

56 Véase Diario de Sesiones del Senado de esa fecha y BOE de 22 de febrero de 1989.

57 Véase Diario de Sesiones del Congreso de esa fecha y BOE de 6 de julio de 1992.

58 Véase BOE de 8 de abril de 1995.

59 Véase Diario de Sesiones del Senado de esa fecha y BOE de 17 de diciembre de 1998.

${ }^{60}$ Véase Diario de Sesiones del Congreso de esa fecha y BOE de 6 de noviembre de 2001.

${ }^{61}$ Véase BOE de 8 de junio de 2004.
} 
Las Cortes Generales nombrarán, en el plazo máximo de dos meses, a los Consejeros de Cuentas del Tribunal en la forma establecida en el apartado 1 del artículo 30 de esta Ley.

Al amparo de esta previsión los primeros consejeros fueron nombrados el 28 y 29 de junio (Senado) y 30 de junio (Congreso) de $1982^{62}$, consiguientemente en tiempo debido. ${ }^{63}$

Lógicamente el mandato de nueve años y la consiguiente renovación debió producirse antes de los mismos días de 1991 o desde la fecha de publicación del nombramiento en el BOE el 21 de julio de 1982. Sin embargo no aconteció hasta el 19 de diciembre de ese mismo año (Congreso y Senado ${ }^{64}$ ), con el consiguiente retraso de cinco meses.

A su vez, este segundo Tribunal de Cuentas debió expirar y ser sustituido por un tercero antes del 20 de diciembre de $2000 \mathrm{y}$, sin embargo, no lo fue hasta el 30 de octubre de 2001 (Congreso $^{65}$ ) y 6 de noviembre de 2001 (Senado), publicándose en el BOE de 7 de noviembre. De este modo se produjo una nueva demora de casi once meses.

Por su parte, la verificación del cumplimiento de los plazos en la elección del Defensor del Pueblo tropieza con la dificultad de que su ley institutiva, la Ley orgánica 3/1981, de 6 de abril, no cuenta con disposición transitoria alguna acerca de la primera elección, momento que serviría de referencia para las elecciones quinquenales posteriores. Ha de acudirse entonces al artículo 4 apartado 2 de dicha ley (antes transcrito), no muy preciso al respecto. Pero tal como se adelantó, la Ley orgánica fue publicada en el BOE de 7 de mayo de 1981 mientras que el primer Defensor del Pueblo apareció designado en el BOE el 30 de diciembre de $1982^{66}$, de lo que resulta que entre un hecho y otro transcurrió más de año y medio, a todas luces excesivo para el espíritu de dicha ley.

Si se toma como referencia esa fecha de 30 de diciembre de 1982, se desprende que el siguiente Defensor tendría que haber sido designado antes del

${ }^{62}$ Véase Diario de Sesiones del Congreso y del Senado de las fechas mencionadas. También el BOE de 21 de julio.

${ }^{63}$ Pues la Ley orgánica del Tribunal de Cuentas (BOE de 21 de mayo) entró en vigor el 10 de junio de 1982.

${ }^{64}$ Véase Diario de Sesiones del Congreso y del Senado de la fecha mencionada. También el BOE de 20 diciembre de 1991.

${ }^{65}$ Coincidiendo con la elección de los miembros del Tribunal Constitucional y del CGPJ.

${ }^{66}$ Para la elección por el Congreso véase Diario de Sesiones del Congreso de los Diputados de 28 de junio de 1982, p. 14680 y ss. 
mismo día de 1987 y sin embargo no lo fue hasta el 16 de marzo de $1988^{67}$, dos meses y medio más tarde.

Mucho más dilatado (un año y ocho meses) fue el retraso del nombramiento del tercer Defensor: se produjo el 1 de diciembre de $1994^{68}$, cuando lógicamente tenía que haberse producido lo más tardar el 16 de marzo de 1993.

Por su parte, el cuarto Defensor del Pueblo debió ser designado antes del 1 de diciembre de 1999, pero no lo fue hasta el 15 de junio de 2000, por tanto con seis meses de retraso.

Finalmente, el quinto Defensor del Pueblo apareció designado el $30 \mathrm{de} \mathrm{ju-}$ nio de $2005^{69}$, lo que debe interpretarse como de cumplimiento del mandato legal. Pudo influir el hecho de que por primera vez fue reelegido el titular saliente.

\section{BIBLIOGRAFÍA UTILIZADA}

AGUIAR DE LUQUE, LUIS Una nueva reflexión sobre la prorogatio de los órganos constitucionales. Una discrepancia y algunas puntualizaciones a J.A. Santamaría, Revista Española de Derecho Constitucional no 85, Enero-Abril 2009.

D'ORAZIO, GIUSTINO Sulla prorogatio dei giudici costituzionali Rivista Trimestrale di Diritto Pubblico julio- septiembre 1966.

ESPÍN TEMPLADO, EDUARDO Comentarios a la ley orgánica del Tribunal Constitucional, coord. Juan Luis Requejo Pagés, Tribunal Constitucional y BOE, Madrid, 2001.

FERNÁNDEZ SEGADO, FRANCISCO Comentarios a la Constitución Española, dirección de O. Alzaga, tomo XII, Edersa Cortes Generales, Madrid, 1999.

KELSEN, HANS Esencia y valor de la democracia, Ed. Labor Barcelona 1934.

LEY, RICHARD, Die Wahl der Mitglieder des Bundesverfassungsgerichtes - Eine Dokumentation anläßlich des 40jährigen Bestehens, Zeitschrift für Parlamentsfragen $3 / 1991$.

PAUNER CHULVI, CRISTINA La designación parlamentaria de cargos públicos, Congreso de los Diputados, Madrid, 2003.

PEREZ CALVO, ALBERTO Comentarios a la Constitución Española, dirección de O. Alzaga, tomo IV, Edersa Cortes Generales, Madrid, 1996.

PIERANDREI, FRANCESCO voz Corte Costituzionale, Enciclopedia del Diritto, Giuffré, tomo X.

\footnotetext{
${ }^{67}$ Véase BOE de la fecha mencionada.

68 Véase BOE de la fecha mencionada.

${ }^{69}$ Véase BOE de la fecha mencionada.
} 
SANTAMARÍA PASTOR, JUAN ALFONSO La prorogatio de los órganos constitucionales. Apuntes minimos sobre un tema que no lo es, Revista Española de Derecho Constitucional $\mathrm{n}^{\circ} 84$, septiembre diciembre 2008.

SANTAOLALLA LÓPEZ, FERNANDO Derecho Parlamentario Español, Editora Nacional, Madrid, 1984.

SÄCKER, HORST Das Bundesverfassungsgericht Oberster Hüter der Verfassung, Bundeszentrale für politische Bildung, Munich 1991.

SCHLAICH, KLAUS Das Bundesverfassungsgericht —Stellung, Verfahren, Entscheidungen-, CH. Beck,sche, Munich, 1991.

TRUJILLO, GUMERSINDO El juicio de legitimidad e interpretación constitucional: cuestiones problemáticas en el horizonte constitucional español, Revista de Estudios Políticos 1979 enero-febrero.

WEBER, ALBRECHT El principio de Estado de derecho como principio constitucional europeo Revista Española de Derecho Constitucional no 84, septiembre diciembre 2008.

\section{Title}

\section{THE PROBLEM OF THE RENEWAL OF THE CONSTITU-} TIONAL ORGANS

\section{Resumen}

En numerosas ocasiones se han incumplido los plazos constitucionales y legales para la elección parlamentaria de los miembros del Tribunal Constitucional, Consejo General del Poder Judicial, Tribunal de Cuentas y Defensor del Pueblo. Esta situación resulta criticable en la medida que implica una vulneración de la Constitución y de importantes leyes. Se exponen diversas soluciones inspiradas en los modelos italiano y alemán: exclusión del mantenimiento en funciones, elección parlamentaria por un sistema proporcional y presentación de candidatos por el propio órgano cuya renovación interesa. Ciertamente, estas medidas podrían evitar buena parte de estas infracciones. Pero también ofrecen serias contrapartidas. Como la raíz del problema reside en las mayorías reforzadas exigidas para la elección por las Cámaras, la solución más coherente y definitiva consistiría en reducir tales mayorías. Aunque lo anterior puede conllevar dificultades jurídicas y políticas no debería excluirse.

\section{Abstract}

In many occasions the constitutional and legal deadlines for the renewal of constitutional bodies have been infringed. That is the case of 
the Constitutional Court, General Council of the Judicial Power, Audit Court and the Defender of the People (Ombudsman). This situation is critical so far it implies a break of the Constitution and important constitutional Acts. Several possible solutions, inspired in German and Italian laws, are considered: exclusion of the provisional extension of the legal term of the holders of these bodies, election by proportional representation within Parliament and candidates been introduced by these bodies after the deadlines expire. These proposals could prevent many of these infringements. But all of them offer important disadvantages. Taking into account that the problem is caused mainly by the reinforced majorities required for the election by the Houses, the appropriate and steadier formula would be to reduce those majorities. Although that means a political and legal challenge, it should not be avoided.

\section{Palabras clave}

Parlamento. Tribunal Constitucional. Consejo General del Poder Judicial. Tribunal de Cuentas. Defensor del Pueblo.

\section{Key words}

Parliament. Constitutional Court. General Council of the Judicial Power. Audit Court. Defender of the People. 
